\title{
Amoebicidal Activity of Milk, Apo-lactoferrin, slgA and Lysozyme
}

\author{
Nidia León-Sicairos, DSc; Fernando López-Soto, MSc; Magda Reyes-López, BSc; Delfino Godínez-Vargas, MSc; \\ Cynthia Ordaz-Pichardo, DSc; and Mireya de la Garza, DSc
}

\begin{abstract}
Objectives: To identify amoebicidal components in human milk and the effect of iron on the amoebicidal activity.

Design: Investigation in axenic cultures of Entamoeba histolytica trophozoites.

Methods: Amoebas were treated with $5 \%-20 \%$ of human, bovine and swine milk, with $10 \%$ of human milk fractions (i.e., casein, proteins except casein and fat) or with I $\mathrm{mg} / \mathrm{ml}$ of human milk apo-lactoferrin, human secretory immunoglobulin type $A(s \mid g A)$ and chicken egg-white lysozyme (i.e., purified proteins). Milk proteins were detected using immunoblot. Confocal microscopy was used to define the interaction of milk proteins ( $100 \mu \mathrm{M}$ each) and amoebas. Experiments were done at least three times in triplicate, and mean and standard deviations were calculated.
\end{abstract}

Results: Human and bovine milk were amoebicidal showing a concentration-dependent effect. The amoebicidal effect was increased in the absence of iron. Milk protein fractions, with the exception of casein, were the components responsible for the amoebicidal activity found. Apo-lactoferrin, slgA and lysozyme were identified in the amoebicidal milk protein fraction. Apo-lactoferrin showed the major amoebicidal effect. These proteins, either alone or in combination, showed a killing effect on the trophozoites. They bound to the amoebic membrane causing cell rounding, lipid disruption and damage.

Conclusions: Milk proteins such as apo-lactoferrin, slgA and lysozyme are able to kill Entamoeba histolytica trophozoites. This study confirms the importance of feeding breast milk to newborns.

Keywords: Amoebicidal; Apo-lactoferrin; Entamoeba histolytica; Lysozyme; Milk; slgA

$\mathrm{M}$

ilk is a widely recognized, healthy, and nutritious source of energy, proteins, vitamins and minerals. In addition to the nutritional value of milk, there has been a growing interest in its capacity to kill microbes, and this knowledge can be applied to feeding recommendations for babies (e.g., breast milk) and also to the production of functional foods for people. ${ }^{1-3}$ Many compounds found in milk exhibit antimicrobial activity. ${ }^{4-9}$ For example, immunoglobulins are protective proteins important in the transfer of passive immunity from the mother to the neonate. ${ }^{10-12}$ In addition to immunoglobulins, other proteins found in milk such as lactoferrin, lactoperoxidase, lysozyme and $N$-acetyl- $\beta$-D-glucosaminidase are thought to have antimicrobial activity. 13,14
Entamoeba histolytica is a pathogenic, parasitic protozoan that can infect the large intestine and cause amoebiasis, an illness responsible for at least 100,000 deaths annually worldwide. The capacity of human milk to kill amoebas ${ }^{6,15}$ and the amoebicidal action of secretory immunoglobulin type A ( $\operatorname{sg} A)^{16}$ have been reported. However, it is unknown which other components of milk are amoebicides. As milk contains several microbicidal components, we fractionated milk and tested each fraction against trophozoites in axenic cultures to describe any amoebicidal effects of other components of human and bovine milk such as lactoferrin, lysozyme and sIgA. We also sought to identify any combined effect among these molecules.
Reprint Requests: Mireya de la Garza, DSc, Departamento de Biología Celular, Centro de Investigación y de Estudios Avanzados del I.P.N., Apdo. 14-740, México, D.F. 07000, México, Tel: 52-55-506I3987, Fax: 52-55-506I3393, Email: mireya@cell.cinvestav.mx
Received: November 14, 2005

Revised: February 14, 2006

Accepted: March 30, 2006
Grant Support: N. León-Sicairos received a scholarship from CONACyT, México (no. 144223) and from El Colegio de Sinaloa (doctoral scholarship in Biomedical Sciences Dr “Hugo Aréchiga Urtuzuastegui”, 2005). 


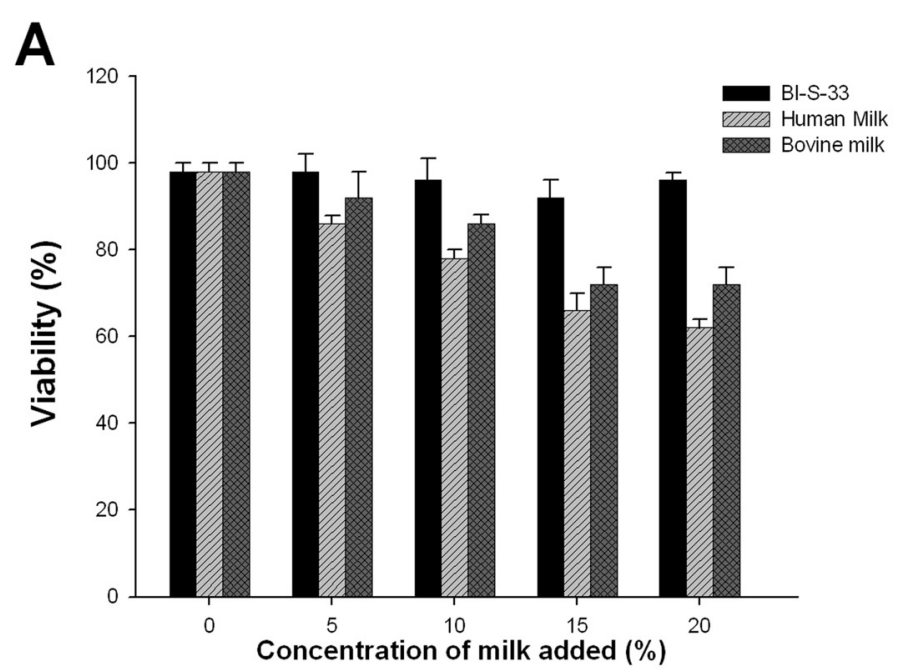

B
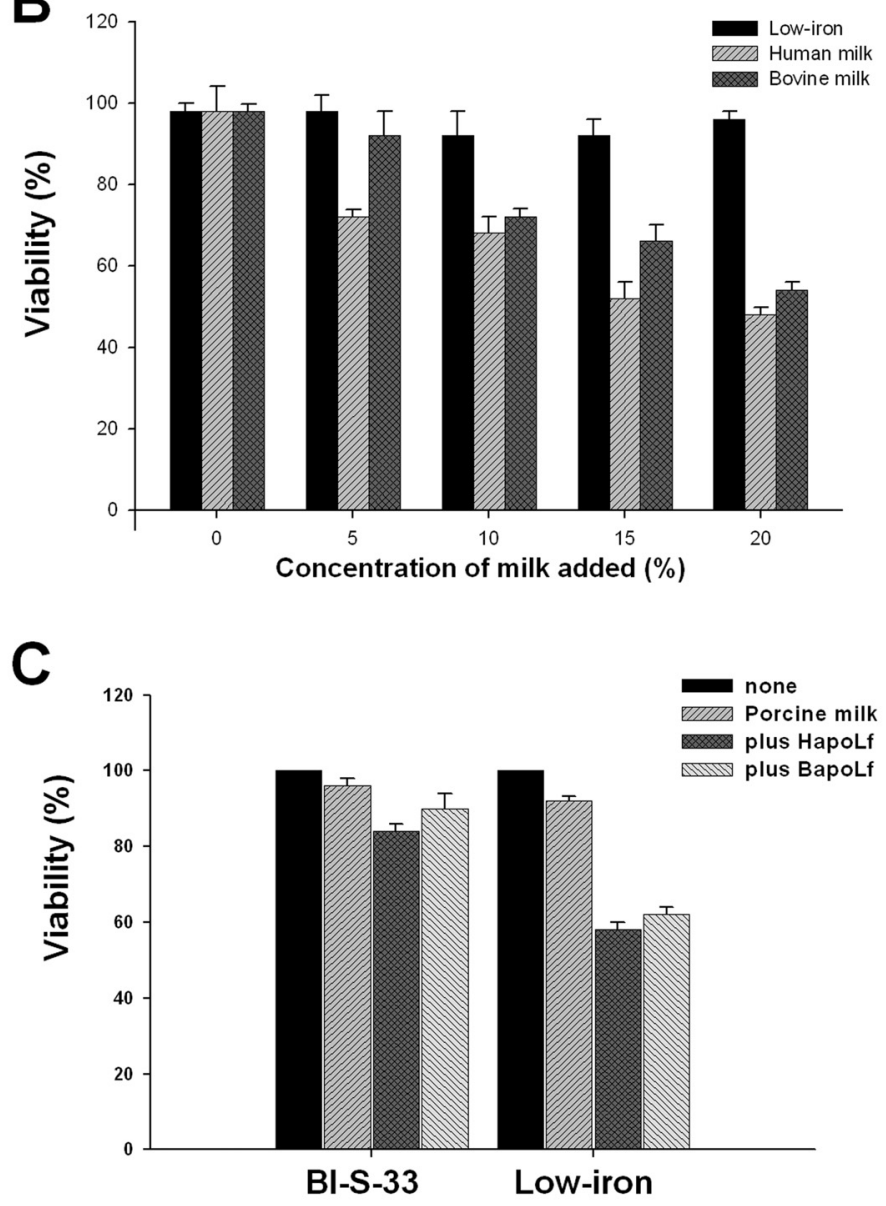

Figure 1. Amoebicidal effect of human and bovine milk. $1 \times 10^{6}$ trophozoites were placed in medium BI-S-33 (A) or in low-iron medium (B), each one containing the percentage of human and bovine milk indicated. (C) Similar to (B), but none or $20 \%$ of porcine milk was used, and $1 \mathrm{mg} / \mathrm{ml}$ of bovine or human apo-lactoferrin were added together with porcine milk. In all cases, the cultures were incubated for 1 hour at $37^{\circ} \mathrm{C}$ and then cells were washed and stained with propidium iodide and trypan blue to determine viability. Experiments were done three times in triplicate. The mean and SD were evaluated.

\section{Materials and Methods}

Amoeba strain and growth conditions

Trophozoites of E. histolytica strain HM-1:IMSS were axenically cultured in BI-S-33 medium ${ }^{17}$ supplemented with $16 \%(\mathrm{v} / \mathrm{v})$ bovine serum (Microlab, Mexico) at $37^{\circ} \mathrm{C}$. A low-iron medium was obtained by using Chelex-100 resin (BioRad, Richmond, VA). ${ }^{18,19}$ Amoebas grown for 48 hours in glass tubes with screw caps containing BI-S-33 medium were chilled on ice baths. This allowed for removal of the amoebas from the tube walls. Next, they were centrifuged at $500 \mathrm{x} \mathrm{g}$ for 10 minutes and were washed twice with phosphate buffered saline (PBS, $\mathrm{pH}$ 7.2).

\section{Milk samples and fractions}

Fresh human milk was donated by two healthy women at 40 days postpartum. Bovine and porcine milk were also used in some experiments. The samples were used either immediately or after storage at $-70^{\circ} \mathrm{C}$. Human milk samples were centrifuged at $4000 \mathrm{x} \mathrm{g}$ for 30 minutes at $4^{\circ} \mathrm{C}$ to remove fat and then again at $30000 \mathrm{x}$ g for 6 hours at $4^{\circ} \mathrm{C}$ to separate the casein pellet. 20,21

\section{Susceptibility to anti-amoebic compounds}

Protozoa suspended in BI-S-33 medium were adjusted to a cell density of $1 \times 10^{6}$ cells $/ \mathrm{ml}$. Experiments were performed following the addition of either milk, milk fractions or purified proteins each with and without iron. Milk samples (i.e., human, bovine and porcine milk) were tested at 5\%,10\%, 15\% and $20 \%$ after a 1 to 3 hour incubation period. Porcine milk was also tested with human and bovine apo-lactoferrin (Morinaga Milk Co., Japan). Human milk fractions were tested at $10 \%$ after 3, 6, 9 and 12 hour incubation periods. Purified proteins (i.e., human milk apo-lactoferrin, human colostrum sIgA and chicken egg-white lysozyme (Sigma-Aldrich, St. Louis, MO)) were added at $1.0 \mathrm{mg} / \mathrm{ml}$ and tested after a 3 hour incubation period. Tubes were mixed carefully by inversion and then incubated at $37^{\circ} \mathrm{C}$ for the times indicated. Lastly, the tubes were chilled on ice baths for 15 minutes. The number of living amoebas was determined by microscopic visualization using the criterion of exclusion of trypan blue dye in a Neubauer hemocytometer or by exclusion of propidium iodide measured by flow cytometry. Dead trophozoites, when they were not destroyed, could be easily recognized by staining with the dyes. Survival was expressed as the average percentage of living organisms in treated cultures in relation to the untreated ones. In flow cytometry assays, the amoebic fluorescence was quantified. Negative controls included media lacking milk, BI-S-33 and low-iron diluted with PBS in order to test the notion that the amoebicidal effect is due to the milk and not to the dilution itself. Each experiment was repeated three to five times in triplicate.

\section{Sodium dodecyl sulfate-polyacrylamide gel electrophoresis (SDS-PAGE) and immunoblot}

Protein concentration was measured,22 and then $20 \mu \mathrm{g}$ protein/well was loaded and run in a $10 \%$ SDS-PAGE by using the method of Laemmli. ${ }^{23}$ To detect the proteins of 


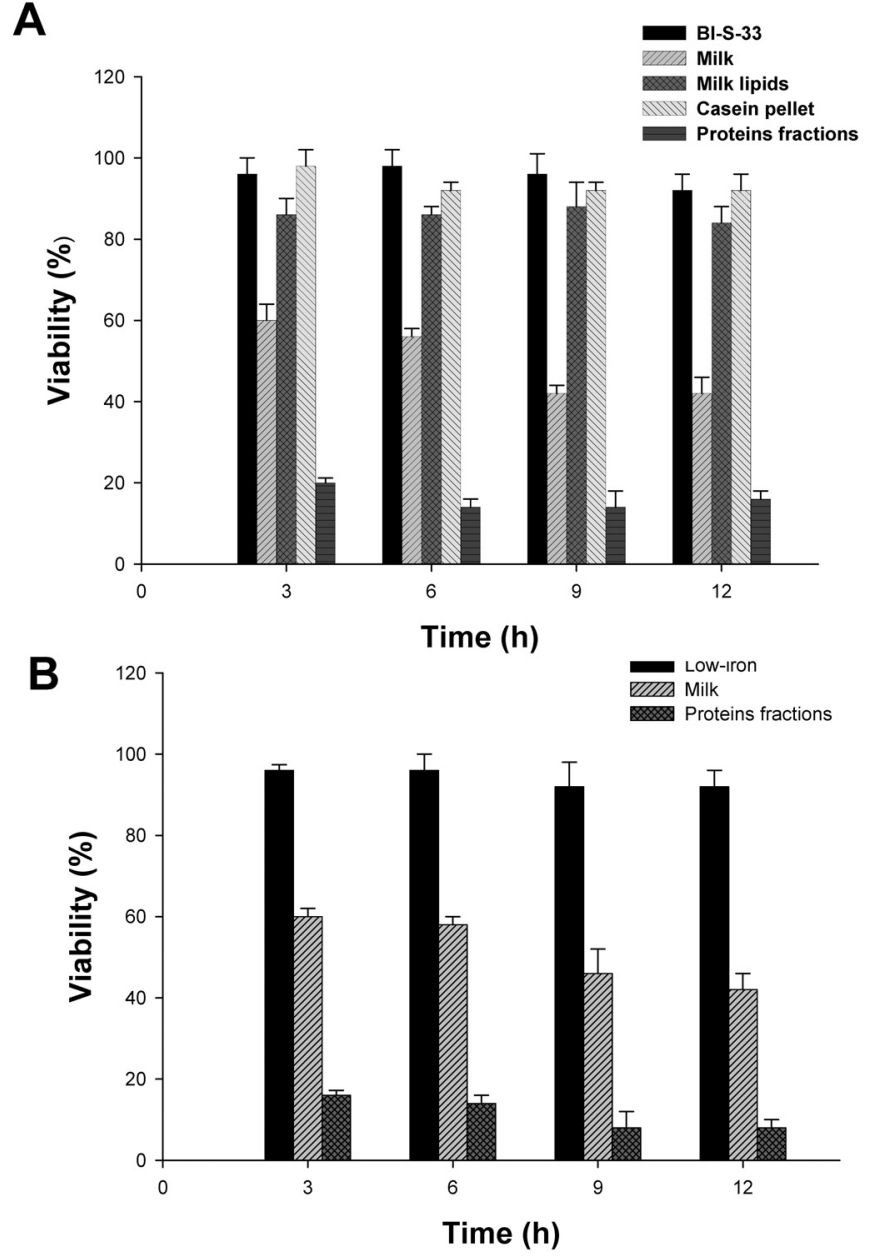

Figure 2. Amoebicidal effect of human milk proteins. $1 \times 10^{6}$ trophozoites were placed in medium BI-S-33 (A) or in low-iron medium (B) containing $10 \%$ of the milk fractions indicated. In both cases, the cultures were incubated for the times indicated at $37^{\circ} \mathrm{C}$ and then cells were washed and stained with propidium iodide and trypan blue to determine viability. Experiments were done three times in triplicate. The mean and SD were evaluated.

interest, the gel was electroblotted to a polyvinylidene difluoride membrane using a transfer apparatus according to the method described by Towbin et al. ${ }^{24}$ After electroblotting, the membrane was blocked at room temperature for 1 hour with $5 \%$ skim milk in PBS containing 0.1\% Tween 20 (PBS-T) (Sigma-Aldrich). It was washed 3 times in PBS-T and was incubated for 1 hour with the following antibodies: mouse $\operatorname{IgG}$ anti-lactoferrin (1:100, Santa Cruz Biotechnology, Santa Cruz, CA), goat IgG anti-IgA (1:100, Zymed Laboratories Inc., San Francisco, CA), and rabbit IgG anti-lysozyme [obtained by us as follows: one rabbit was inoculated with $50 \mu \mathrm{g}$ of chicken egg-white lysozyme (Sigma-Aldrich) every week; the first inoculation was delivered subcutaneously, and three boosts were delivered intramuscularly. $\operatorname{IgG}$ was purified by using the monoRec Ab column (Zymed Laboratories, Inc.), as indicated by the manufacturer]. After 3 washes with PBS-T, the membrane was incubated for 1 hour with horseradish peroxidase-protein A (1:10000 in PBS-T), washed with PBS-T, and incubated with 3,3-diaminobenzidine. Color reaction was developed using $\mathrm{H}_{2} \mathrm{O}_{2}$.

\section{Confocal microscopy}

Trophozoites were treated for 1 hour with $100 \mu \mathrm{M}$ each of the following proteins: FITC-apo-lactoferrin, sIgA and lysozyme. They were then washed twice with PBS and fixed with $4 \%$ paraformaldehyde for 1 hour at $37^{\circ} \mathrm{C}$. Next, amoebas were washed, permeabilized with $2.5 \%$ Triton X100 for 5 minutes at $37^{\circ} \mathrm{C}$, washed and incubated for 1 hour at $37^{\circ} \mathrm{C}$ with the polyclonal antibodies anti-IgA and anti-lysozyme. Cells were then washed and incubated for 1 hour with secondary antibodies coupled to Cy5 (1:100, Zymed Laboratories, Inc.) to detect lysozyme and IgA. In order to determine whether these proteins affected the amoebic lipids pattern, parasites were stained with $100 \mu \mathrm{g} / \mathrm{ml}$ Nile red (Sigma-Aldrich) for 30 minutes, washed and their fluorescence intensity was estimated under flow cytometry. Stained trophozoites were then incubated with $1 \mathrm{mg} / \mathrm{ml}$ each of the three proteins together and fixed. The fluorescence intensity was measured, and samples were prepared for confocal microscopy.

\section{Results and Discussion}

\section{Human and bovine milk are amoebicidal}

In the presence of iron, the microbicidal effect was observed when the trophozoites were incubated for 1 hour in $5 \%, 10 \%$, $15 \%$ and $20 \%$ of human fresh milk $(86 \%, 78 \%, 66 \%$ and $62 \%$ viability, respectively; figure $1 \mathrm{~A})$. Bovine milk showed a slightly lower amoebicidal activity than human milk, although only the result with $20 \%$ bovine milk was statistically significant (figure 1A). After 3 hours of incubation, a similar amoebicidal effect was observed (data not shown). The dilution of media did not have an effect on the amoeba culture viability, at least until the third hour.

The lethal achievement for both human and bovine milk was increased when amoebas were incubated in the absence of iron (i.e., $72 \%, 68 \%, 52 \%$ and $48 \%$ with $5 \%, 10 \%, 15 \%$ and $20 \%$ of human milk, respectively; figure 1B). The principal microbicidal component of human milk was the protein apo-lactoferrin. We tested the capacity of porcine milk, which has a low concentration of apo-lactoferrin, in order to provide evidence for the participation of apo-lactoferrin as a milk amoebicidal component. Interestingly, porcine milk did not have an amoebicidal effect (i.e., $>90 \%$ viability). However, the cidal activity was observed when human or bovine apo-lactoferrin was added to the milk (i.e., $52 \%$ and $66 \%$, respectively; figure 1C). Therefore, the milk amoebicidal effect was concentration-dependent and increased in the absence of iron. Milk proteins such as apo-lactoferrin, one of the microbicidal proteins found in this fluid that mainly exerts its action in the iron-free state and acts in synergism with lysozyme and IgA, may be responsible for this effect. ${ }^{25}$ This idea is reinforced by results we obtained in which apo-lactoferrin added to the BI-S-33 medium changed its saturation state to hololactoferrin, which was used by amoebas as an iron source. ${ }^{26}$ In addition, iron has been implied in the pathogen's resistance to certain compounds. ${ }^{25,27-29}$ 
A
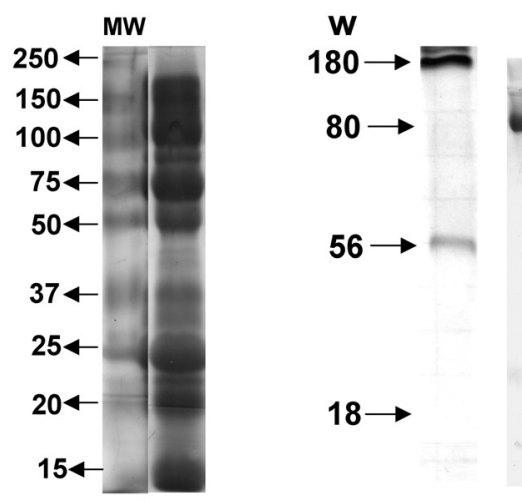

H Lysozyme

Figure 3. Proteins with amoebicidal activity identified in human milk. (A) Proteins of human milk and from the fraction enriched in proteins were loaded (30 $\mu \mathrm{g} / \mathrm{well})$ in gels and separated by SDS-PAGE. (B) Gels were electroblotted to a nitrocellulose membrane and then incubated with antibodies against IgA, lactoferrin and lysozyme. A secondary antibody coupled to horseradish peroxidase was used and the color reaction was revealed by the 3,3-diaminobenzidine method.

Swine milk had no effect against $E$. histolytica trophozoites. There is a smaller proportion of lactoferrin in porcine than in human milk, and it is less efficient than other lactoferrins. ${ }^{30}$ This result suggests that apo-lactoferrin is one of the amoebicidal compounds of human milk, which could act alone or in combination with other milk proteins.

Amoebicidal effect of human milk is due to the protein fraction, with the exception of casein

The assumption that the observed killing effect of milk was produced by its proteins was corroborated by testing milk fractions on E. histolytica cultures. Milk samples were centrifuged in order to separate the casein pellet, lipids and the remaining proteins, and then each of these fractions was added to the medium containing trophozoites. After a 1 hour incubation period, the samples enriched in proteins showed amoebicidal activity, but cultures in which lipids or casein were added maintained viability (figure 2A). Ten percent milk proteins significantly reduced the trophozoite number (i.e., $26 \%, 20 \%, 14 \%, 14 \%$ and $16 \%$ viability of amoebas after 1 , $3,6,9$ and 12 hours of incubation, respectively; figure $2 \mathrm{~A}$ ) compared with $20 \%$ whole milk (i.e., $62 \%, 60 \%, 56 \%, 42 \%$ and $42 \%$ viability at the same times). Again, when iron was removed from the culture medium, the cidal effect displayed by the fraction containing proteins was higher (i.e., $16 \%, 14 \%$, $8 \%$ and $8 \%$ after $3,6,9$ and 12 hours of incubation, respectively; figure $2 \mathrm{~B}$ ) than that in the iron-containing medium BI-S-33. Interestingly, the amoebicidal effect in all cases was marked in the first hours of interaction. Lipid fraction had low amoebicidal activity (i.e., $12 \%$ to $15 \%$ inhibition). These results show that proteins of milk, with the exception of casein which had little effect (i.e., approximately $8 \%$ to $10 \%$ of inhibition), attack the amoeba trophozoites. Casein is an anionic protein involved in the transport of ions, mainly calcium. Also, it has been reported that after digestion with pepsin and trypsin, resulting peptides have an antibacterial action against gram-positive bacteria, ${ }^{31}$ but other peptides kill gram-negative ones. ${ }^{32}$ Casein is also a cysteine-protease inhibitor. ${ }^{32}$ Perhaps casein does not have a direct amoebicidal action because its target sites may not be present in E. histolytica, and the amoebic cysteine-proteases and calcium transport are not affected by casein. Apparently, milk proteins without casein resulted in higher amoebicidal activity than whole milk. These components from the protein fraction are concentrated in comparison with those from whole milk. However, lipids and casein, which are also concentrated in fractions, had no amoebicidal effect.

Secretory IgA, lactoferrin and lysozyme are among the amoebicidal components of milk

In order to determine which components were present in the milk protein-enriched fraction, it was separated by SDS-PAGE. Figure $3 \mathrm{~A}$ shows the protein fraction profile. When the profile was electrotransferred to a nitrocellulose membrane and probed with specific antibodies, we identified sIgA, lactoferrin (i.e., apo-lactoferrin) and lysozyme (figure 3B, columns 1,2 and 3 , respectively). Therefore, we next corroborated the participation of these proteins in the amoebicidal activity. Results showed that purified sIgA, apo-lactoferrin and lysozyme were amoebicidal since the first hour of interaction (i.e., $1 \mathrm{mg} / \mathrm{ml}$ each at 3 hours of incubation; figure 4). In all experiments, apo-lactoferrin showed the highest amoebicidal activity followed by sIgA. Lysozyme always showed the lowest cidal activity (i.e., viability of $62 \%$, $66 \%$ and $78 \%$, respectively, in low-iron medium; figure 4). Also, a mixture of these three proteins was tested. Results showed that the three proteins have a combined effect against amoebas (i.e., $12 \%$ viability in low-iron medium; figure 4).

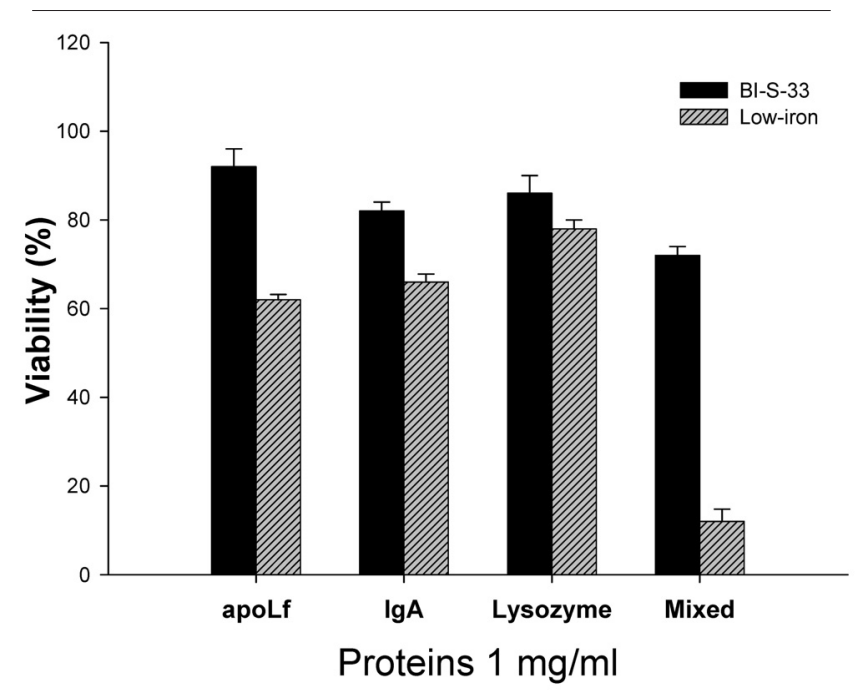

Figure 4. Combined activity of apo-lactoferrin, $\lg \mathrm{A}$ and lysozyme against $E$. histolytica trophozoites. $1 \times 10^{6}$ trophozoites were placed in $\mathrm{BI}-\mathrm{S}-33$ or in low-iron media and then $1 \mathrm{mg} / \mathrm{ml}$ of apo-lactoferrin, IgA and lysozyme were added, each alone or mixed. After 3 hours of incubation, trophozoites were washed and stained with trypan blue to assess viability. Experiments were done three times in triplicate. The mean and SD were evaluated. 

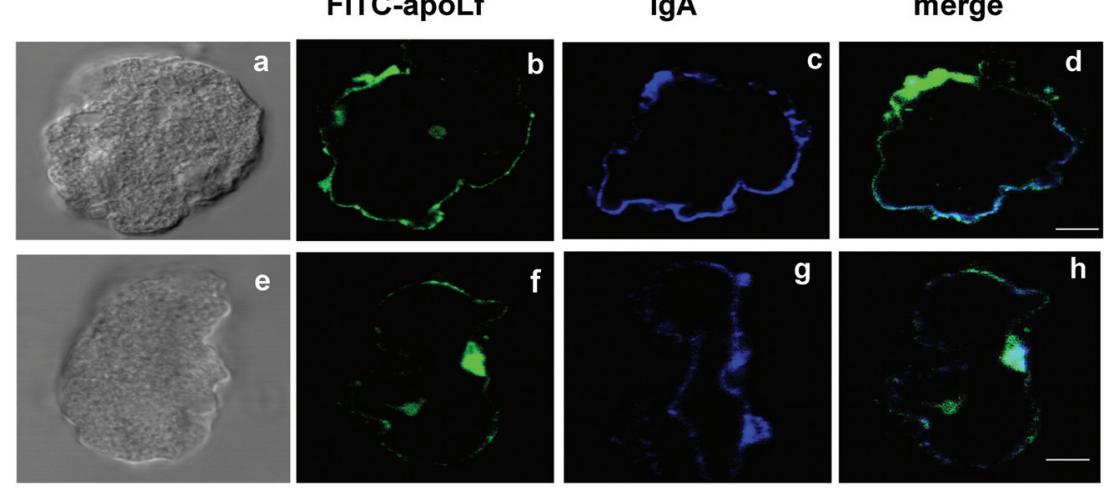

FITC-apoLf

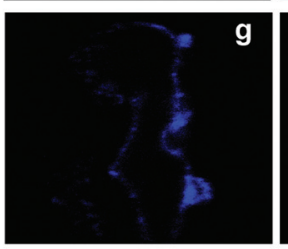

Lysozyme

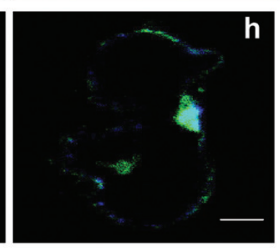

merge

\section{B}
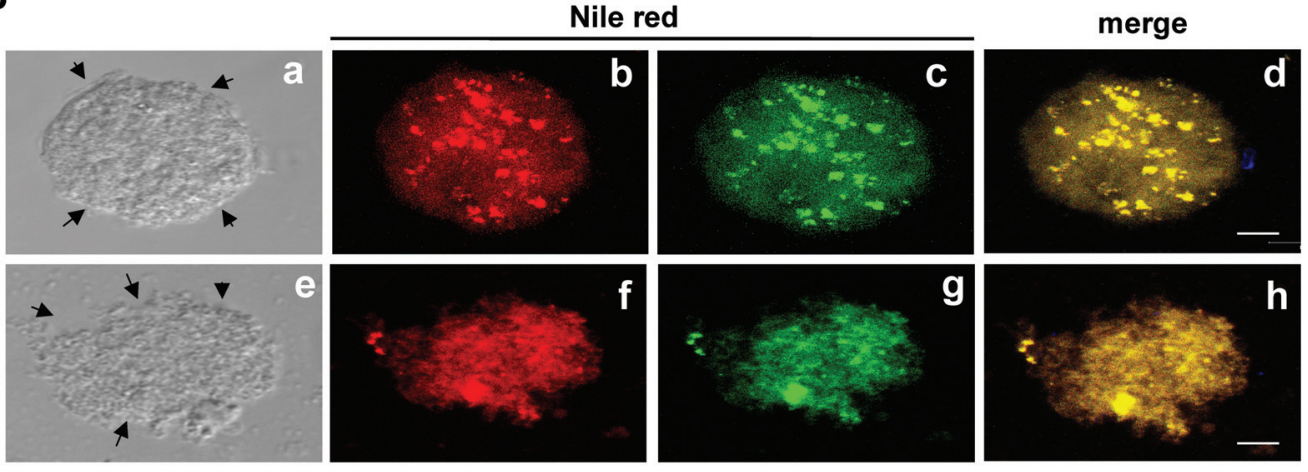

Nile red + apoLf + IgA + lysozyme

Figure 5. Proteins of human milk bound to amoebic surface and damaged the trophozoites. (A) Amoebas (1x10 5 ) were placed onto slides and then washed and incubated with FITC-apo-lactoferrin or unlabeled IgA and lysozyme (100 $\mu \mathrm{M}$ each). After 1 hour, samples were washed and incubated with anti-IgA or with anti-lysozyme for 1 hour, washed and incubated with secondary antibodies coupled to Cy5. (B) $1 \times 10^{6}$ trophozoites were treated with Nile red for 30 minutes, washed and treated with IgA, apo-lactoferrin and lysozyme $\left(1 \mathrm{mg} / \mathrm{ml}\right.$ each) for 1 hour. All experiments were done at $37^{\circ} \mathrm{C}$. Samples were processed to be analyzed by confocal microscopy. Arrows signal in (e) the damaged membranes, and photos are representative of the amoebic population. Bar, $8 \mu \mathrm{M}$.

However, as iron was added to the culture, the killing effect was diminished. The main cidal effect was probably due to apo-lactoferrin (figure 4).

Previously we have reported that apo-lactoferrin is observed on amoebic surfaces within the first 5 minutes of interaction with trophozoites, and the amoebas died following the interaction. ${ }^{26}$ In order to explore whether SIgA and lysozyme are also bound by the amoebic membrane, we performed assays by confocal microscopy using probes with different fluorochromes (i.e., FITC and CY5). sIgA and lysozyme were observed on the membrane of amoebas co-localizing with apo-lactoferrin (figure 5A), although each one was also bound by amoebas in other sites (figure 5A, panels $d$ and $h$ ). It has been suggested that apo-lactoferrin and its peptide, lactoferricin, can affect pathogens by interacting with their membrane lipids resulting in injury of the lipid phase and thereby causing changes in membrane permeability and lysis. 25,33

In other experiments, amoebas treated with the mixture of apo-lactoferrin, IgA and lysozyme were stained with Nile red in order to see cellular damage (figure 5B). Amoebas showed damage, rearrangement and disruption of lipids and were lysed in only 30 minutes of interaction with the three proteins (figure 5B, panels e-h) in comparison with amoebas without treatment which showed a typical morphology and lipid staining (figure $5 \mathrm{~B}$, panels a-d). These data suggest that apo-lactoferrin combined with $\operatorname{IgA}$ and lysozyme caused changes and disruption in the lipid pattern after being bound on the amoebic membrane. The experiments using propidium iodide suggest that the cell surface of the amoeba was damaged, because this dye only crosses permeabilized membranes. Thus, one of the targets for these three proteins could be some lipids.

Although the sensitivity of E. histolytica toward sIgA, apo-lactoferrin and lysozyme was assayed in vitro, the parasites might also be affected in vivo due to the presence of these proteins in the large intestine, the area where E. histolytica infection occurs. Lactoferrin is a natural component of mothers' milk. It is also found in all secretions that bathe the mucous membranes and is released from neutrophiles at infection sites. Lactoferrin is concentrated in oral cavities and comes in direct contact with pathogens 
killing them through a variety of different mechanisms. ${ }^{25,34,35}$ Thus, it is a first-line, innate immune defense in the human body. ${ }^{33}$ Lactoferrin also acts on the immune system. Exactly how it exerts the modulating function is not entirely clear. Specific receptors for lactoferrin are found in many key cells such as lymphocytes, monocytes and macrophages, and it is directly involved in the upregulation of natural killer (NK) cell activity. Most research points to lactoferrin as being more of an immune modulator rather than a simple stimulant of immunity. Thus, lactoferrin appears to be particularly important in the health and function of the intestinal tract. It greatly reduces inflammation in some bowel diseases, ${ }^{36}$ and lactoferrin concentration has been found to be augmented in the large intestine in patients with colitis or active ulcerative colitis, colon cancer, ${ }^{37}$ colon disorders and in other pathologies. ${ }^{38}$ These results indicate the crucial participation of lactoferrin at the large intestine level. Although we do not have data of fecal lactoferrin content during intestinal amoebiasis, it is probably increased by the neutrophiles degranulation, and lactoferrin could be acting against E. histolytica trophozoites.

Perhaps lactoferrin could be effective against intestinal amoebiasis. However, it must be administered in the free-iron state (i.e., apo-lactoferrin) and probably in enteric-coated formulas that permit passage through the site infected by $E$. histolytica in the colon. In the case of hepatic amoebiasis, the peptides derived from lactoferrin generated in the stomach by the action of pepsin absorbed in the small intestine can act throughout the body and ultimately reach the liver. Importantly, in animal models, the oral supplementation of vitamin A and lactoferrin has influenced growth of the ileum and colon. ${ }^{39}$ Published studies that have examined the use of lactoferrin as a food supplement and its effects on immunity have been quite promising. Researchers using various animal models have found that the ingestion of lactoferrin has a direct protective effect on the regulation and modulation of the immune system. ${ }^{40,41}$ Indeed, lactoferrin and its $\mathrm{N}$-amino derived peptide, lactoferricin, are already used in therapy against pathogenic microorganisms and for several types of cancer in animal models and in patients. ${ }^{40}$ For example, one study that examined the immune response to the bacterial lipopolysaccharide found that feeding lactoferrin to mice dramatically reduced the lethality of this endotoxin and improved the immune response parameters. 42 Another study with baby pigs reported that only $17 \%$ of the animals died when fed lactoferrin and simultaneously injected with the Escherichia coli endotoxin, as opposed to $74 \%$ of pigs dying that were not fed lactoferrin. ${ }^{43}$ This could be a major finding, as septic shock is the most frequent cause of death for intensive care patients and the thirteenth leading cause of death in the United States. A study using healthy human volunteers found that the ingestion of lactoferrin derived from bovine milk had positive immunoregulatory effects that were specific to the individual, and that lactoferrin may be applied in the clinic to improve the immune status of the patients. ${ }^{44}$
The main immunoglobulin in human milk is sIgA. E. histolytica contains surface antigens that interact with specific human immune sera; for example, the $260-\mathrm{kDa}$ galactose-inhibitable lectin elicits serum and intestinal sIgA that have in vitro inhibitory activity. ${ }^{45}$ Furthermore, a known serine-rich protein isoform, a $29 \mathrm{kDa}$ cysteine-rich protein, the $\alpha$ - and $\beta$-elongation factor, and the glutamic acid-peptide are recognized by sIgA antibodies. ${ }^{46}$ IgA also inhibits amoebic proteolytic activities in vitro. ${ }^{47}$ In asymptomatic carriers, the recognition of the E. histolytica $115-\mathrm{kDa}$ surface protein by human SIgA has been reported. ${ }^{48}$ In fact, it has been postulated for use in the vaccination with the E. histolytica Gal/Gal lectin, a molecule implicated in mediate parasite adherence to the colonic surface. ${ }^{49}$ In this work, we found a reduction of the E. histolytica trophozoite culture viability with human milk. As the milk donors were healthy persons without symptoms of amoebiasis or history of bowel inflammation, the milk used did not have increased anti-amoebic sIgA antibodies. However, these milk donors may have been carrying Entamoeba dispar, the non-pathogenic amoeba, and $\operatorname{sig} \mathrm{A}$ antibodies might recognize some antigens shared by $E$. histolytica and E. dispar. Akisu et al ${ }^{15}$ had similar results with milk from healthy lactating mothers. Undoubtedly, the presence of induced SIgA antibodies against $E$. histolytica in milk is important for protection of babies.

Interestingly, non-induced commercial sIgA was strongly bound to the amoebic surface in some sites co-localizing with apo-lactoferrin. This result suggests the presence of a receptor for this protein in the E. histolytica trophozoites, which remains to be determined. The binding of IgA to the amoebic surface could signal cellular death. In E. coli, non-immune binding of human $\operatorname{IgA}$ and $\operatorname{IgG} \mathrm{Fc}$ by distinct sequence segments of a cellular surface has been reported. This immunoglobulin-binding protein is also present in other bacteria. 50

Lysozyme is an enzyme present in milk and secretions of some mammalian species, especially in humans. ${ }^{14}$ Lysozyme concentration is higher in human colostrum and pre-colostral milk than in mature milk, and it acts against a wide number of bacterial species. Lysozyme kills bacteria by hydrolysis of the $N$-acetylmuramyl-(1-4)- $\beta$-linkages of the peptidoglycan constituent of the bacterial cell wall. ${ }^{14,51}$ Since we found that lysozyme acted slightly against the amoeba and since this parasite lacks a cell wall, perhaps the amoebic membrane possesses a similar component to the bacterial peptidoglycan. A candidate could be the lipopeptidophosphoglycan, which was described by Isibasi et al. ${ }^{52}$ However, lysozyme was not effective against Giardia lamblia, a parasitic protozoan that infects the small intestine. ${ }^{6}$ Lysozyme usually functions in association with lactoferrin, $\operatorname{sIgA}$ and other microbicidal compounds. ${ }^{53}$ For example, lysozyme is effective against $E$. coli in concert with sIgA, and it causes lysis of some species of Salmonella in association with ascorbate and peroxide which are both present at low concentrations in milk. ${ }^{51}$ Lysozyme can limit the migration of neutrophils into damaged tissue and might function as an anti-inflammatory agent. ${ }^{54}$ 
To our knowledge this is the first report on the killing activity of milk protein components against the protozoan parasite $E$. histolytica. The only work concerning the effect of lysozyme and complement-dependent lysis of E. histolytica was reported 20 years ago. ${ }^{55}$ Although the biological activity of these compounds has been previously demonstrated for viruses, bacteria and yeasts, there is little known about the molecular basis of their killing activities. $6,9,15$ In the case of apo-lactoferrin, it has potential as a new therapeutic agent for inflammatory bowel disease. ${ }^{56}$ It is important to say that apo-lactoferrin affects pathogens such as Salmonella enterica serovar Typhimurium and E. coli without inhibiting the growth of bifidobacteria. These data suggest that lactoferrin may have the potential to be combined with probiotic bacteria in biotherapeutic products, which could help to balance human gut microflora and limit the overgrowth of certain pathogenic microorganisms, ${ }^{57}$ including parasites. In conclusion, the observed specific effect of physiologically occurring proteins against E. histolytica may open up a new approach for drug development against this protozoan parasite.

\section{Acknowledgments}

We thank Q.F.B. Blanca Reyes for her efficient support in the Flow Cytometry and Confocal Microscopy Units of CINVESTAV-IPN. We also thank Esteban Molina for excellent technical assistance and Morinaga Milk for the generous donation of bovine lactoferrin.

\section{References}

1. Chance G. Premie nutrition: mother's milk may be best. Can Med Assoc J 1981;124:1247-1248.

2. Lawrence PB. Breast milk. Best source of nutrition for term and preterm infants. Pediatr Clin North Am 1994;41:925-941.

3. Tomita M, Wakabayashi H, Yamauchi K, Teraguchi S, Hayasawa H. Bovine lactoferrin and lactoferricin derived from milk: production and applications. Biochem Cell Biol 2002;80:109-112.

4. Avery VM, Gordon DL. Antibacterial properties of breast milk: requirements for surface phagocytosis and chemiluminescence. Eur J Clin Microbiol Infect Dis 1991;10:1034-1039.

5. Finn A, Zhang Q, Seymour L, Fasching C, Pettitt E, Janoff EN. Induction of functional secretory IgA responses in breast milk, by pneumococcal capsular polysaccharides. J Infect Dis 2002;186:1422-1429.

6. Gillin FD, Reiner DS, Wang CS. Human milk kills parasitic intestinal protozoa. Science 1983;221:1290-1292.

7. Gillin FD, Reiner DS, Wang CS. Killing of Giardia lamblia trophozoites by normal human milk. J Cell Biochem 1983;23:47-56.

8. Sigman M, Burke KI, Swarner OW, Shavlik GW. Effects of microwaving human milk: changes in IgA content and bacterial count. J Am Diet Assoc 1989;89:690-692.

9. Goldman AS, Smith CW. Host resistance factors in human milk. J Pediatr 1973;82:1082-1090.

10. Mata LJ, Wyatt RG. The uniqueness of human milk. Host resistance to infection. Am J Clin Nutr 1971;24:976-986.

11. Korhonen H, Marnila P, Gill HS. Milk immunoglobulins and complement factors. Br J Nutr 2000;84:S75-S80.

12. Rodriguez-Palmero M, Koletzko B, Kunz C, Jensen R. Nutritional and biochemical properties of human milk: II. Lipids, micronutrients, and bioactive factors. Clin Perinatol 1999;26:335-359.
13. Lonnerdal B. Human milk proteins: key components for the biological activity of human milk. Adv Exp Med Biol 2004;554:11-25.

14. Hamosh M. Protective function of proteins and lipids in human milk. Biol Neonate 1998;74:163-176.

15. Akisu C, Aksoy U, Cetin H, Ustun S, Akisu M. Effect of human milk and colostrum on Entamoeba histolytica. World J Gastroenterol 2004;10:741-742.

16. Abou-el-Magd I, Soong CJ, el-Hawey AM, Ravdin JI. Humoral and mucosal IgA antibody response to a recombinant $52-\mathrm{kDa}$ cysteine-rich portion of the Entamoeba histolytica galactose-inhibitable lectin correlates with detection of native $170-\mathrm{kDa}$ lectin antigen in serum of patients with amebic colitis. J Infect Dis 1996;174:157-162.

17. Diamond LS, Harlow DR, Cunnick CC. A new medium for the axenic cultivation of Entamoeba histolytica and other Entamoeba. Trans R Soc Trop Med Hyg 1978;72:431-432.

18. Serrano-Luna JJ, Negrete E, Reyes M, de la Garza M. Entamoeba histolytica HM1:IMSS: hemoglobin-degrading neutral cysteine proteases. Exp Parasitol 1998;89:71-77.

19. Reyes-Lopez M, Serrano-Luna JJ, Negrete-Abascal E, Leon-Sicairos N, Guerrero-Barrera AL, de la Garza M. Entamoeba histolytica: transferrin binding proteins. Exp Parasitol 2001;99:132-140.

20. Aisen P, Leibman A. Lactoferrin and transferrin: a comparative study. Biochim Biophys Acta 1972;257:314-323.

21. Shin K, Hayasawa H, Lonnerdal B. Purification and quantification of lactoperoxidase in human milk with use of immunoadsorbents with antibodies against recombinant human lactoperoxidase. Am J Clin Nutr 2001;73:984-989.

22. Bradford MM. A rapid and sensitive method for the quantitation of microgram quantities of protein utilizing the principle of protein-dye binding. Anal Biochem 1976;72:248-254.

23. Laemmli UK. Cleavage of structural proteins during the assembly of the head of bacteriophage T4. Nature 1970;227:680-685.

24. Towbin H, Staehelin T, Gordon J. Electrophoretic transfer of proteins from polyacrylamide gels to nitrocellulose sheets: procedure and some applications. Proc Natl Acad Sci U S A 1979;76:4350-4354.

25. Orsi N. The antimicrobial activity of lactoferrin: current status and perspectives. Biometals 2004;17:189-196.

26. Leon-Sicairos N, Reyes-Lopez M, Canizalez-Roman A, Bermudez-Cruz RM, Serrano-Luna J, Arroyo R, de la Garza M. Human hololactoferrin: endocytosis and use as an iron source by the parasite Entamoeba histolytica. Microbiology 2005; 151:3859-3871.

27. Kostrova IuM, Shekhovtseva NV. Antibiotic resistance of hemolytic bacteria, depending on iron content in bacterial cells. Zh Mikrobiol Epidemiol Immunobiol 2005;(4):75-77.

28. Pradines B, Rogier C, Fusai T, Mosnier J, Daries W, Barret E, Parzy D. In vitro activities of antibiotics against Plasmodium falciparum are inhibited by iron. Antimicrob Agents Chemother 2001;45:1746-1750.

29. Weinberg ED. Roles of iron in infection and neoplasia. J Pharmacol 1985;16:358-364.

30. Teng CT. Lactoferrin gene expression and regulation: an overview. Biochem Cell Biol 2002;80:7-16.

31. Baranyi M, Thomas U, Pellegrini A. Antibacterial activity of casein-derived peptides isolated from rabbit (Oryctolagus cuniculus) milk. J Dairy Res 2003;70:189-197.

32. Ohashi A, Murata E, Yamamoto K, Majima E, Sano E, Le QT, Katunuma N. New functions of lactoferrin and beta-casein in mammalian milk as cysteine protease inhibitors. Biochem Biophys Res Commun 2003;306:98-103.

33. Farnaud S, Evans RW. Lactoferrin - a multifunctional protein with antimicrobial properties. Mol Immunol 2003;40:395-405. 
34. Weinberg ED. Human lactoferrin: a novel therapeutic with broad spectrum potential. J Pharm Pharmacol 2001;53:1303-1310.

35. Artym J, Zimecki M. The role of lactoferrin in the proper development of newborns. Postepy Hig Med Dosw (Online) 2005;59:421-432.

36. Brock JH. Lactoferrin in human milk: its role in iron absorption and protection against enteric infection in the newborn infant. Arch Dis Child 1980;55:417-421.

37. Uchida K, Matsuse R, Tomita S, Sugi K, Saitoh O, Ohshiba S. Immunochemical detection of human lactoferrin in feces as a new marker for inflammatory gastrointestinal disorders and colon cancer. Clin Biochem 1994;27:259-264.

38. Sukharev AE, Nikolaev AA, Vasil'ev M. Serum lactoferrin level in normal conditions and in pathology. Vopr Med Khim 1990;36:81-83.

39. Schottstedt T, Muri C, Morel C, Philipona C, Hammon HM, Blum JW. Effects of feeding vitamin A and lactoferrin on epithelium of lymphoid tissues of intestine of neonatal calves. J Dairy Sci 2005;88:1050-1061.

40. Weinberg ED. The therapeutic potential of lactoferrin. Expert Opin Investig Drugs 2003;12:841-851.

41. Brock JH. The physiology of lactoferrin. Biochem Cell Biol 2002;80:1-6.

42. Sasaki Y, Otsuki K, Hasegawa A, Sawada M, Chiba H, Negishi M, Nagatsuka M, Okai T. Preventive effect of recombinant human lactoferrin on lipopolysaccharide-induced preterm delivery in mice. Acta Obstet Gynecol Scand 2004;83:1035-1038.

43. Lee WJ, Farmer JL, Hilty M, Kim YB. The protective effects of lactoferrin feeding against endotoxin lethal shock in germfree piglets. Infect Immun 1998;66:1421-1426.

44. Zimecki M, Wlaszczyk A, Cheneau P, Brunel AS, Mazurier J, Spik G, Kubler A. Immunoregulatory effects of a nutritional preparation containing bovine lactoferrin taken orally by healthy individuals. Arch Immunol Ther Exp (Warsz) 1998;46:231-240.

45. Ravdin JI, Shain DC, Kelsall BL. Antigenicity, immunogenicity and vaccine efficacy of the galactose-specific adherence protein of Entamoeba histolytica. Vaccine 1993;11:241-246.

46. Carrero JC, Petrossian P, Acosta E, Sanchez-Zerpa M, Ortiz-Ortiz L, Laclette JP. Cloning and characterization of Entamoeba histolytica antigens recognized by human secretory $\operatorname{IgA}$ antibodies. Parasitol Res 2000;86:330-334.

47. Guerrero-Manriquez GG, Sanchez-Ibarra F, Avila EE. Inhibition of Entamoeba histolytica proteolytic activity by human salivary IgA antibodies. APMIS 1998;106:1088-1094

48. Barbosa-Sabanero G, Avila EE. Recognition of Entamoeba histolytica $115-\mathrm{kDa}$ surface protein by human secretory immunoglobulin A antibodies from asymptomatic carriers. J Parasitol 2004;90:373-378.

49. Houpt E, Barroso L, Lockhart L, Wright R, Cramer C, Lyerly $\mathrm{D}$, Petri WA. Prevention of intestinal amebiasis by vaccination with the Entamoeba histolytica Gal/GalNac lectin. Vaccine 2004;22:611-617.

50. Sandt $\mathrm{CH}$, Hill CW. Nonimmune binding of human immunoglobulin A (IgA) and $\operatorname{IgG} \mathrm{Fc}$ by distinct sequence segments of the EibF cell surface protein of Escherichia coli. Infect Immun 2001;69:7293-7303.

51. Masschalck B, Van Houdt R, Van Haver EG, Michiels CW. Inactivation of gram-negative bacteria by lysozyme, denatured lysozyme, and lysozyme-derived peptides under high hydrostatic pressure. Appl Environ Microbiol 2001;67:339-344.

52. Isibasi A, Santa Cruz M, Soto Montano X, Ramirez A, Kumate J. Localization of a lipopeptidophosphoglycan extracted by phenol-water from trophozoites of the HK-9 strain of Entamoeba histolytica. Arch Invest Med (Mex) 1982;13:57-62.
53. Branen JK, Davidson PM. Enhancement of nisin, lysozyme, and monolaurin antimicrobial activities by ethylenediaminetetraacetic acid and lactoferrin. Int J Food Microbiol 2004;90:63-74.

54. Gordon LI, Douglas SD, Kay NE, Yamada O, Osserman EF, Jacob HS. Modulation of neutrophil function by lysozyme. Potential negative feedback system of inflammation. J Clin Invest 1979;64:226-232.

55. Mogyoros M, Fishelson Z, Gitler C. Lysozyme and complement-dependent lysis of Entamoeba histolytica. Inhibition by leupeptin. Isr J Med Sci 1986;22:918-920.

56. Togawa J, Nagase H, Tanaka K, Inamori M, Umezawa T, Nakajima A, Naito M, Sato S, Saito T, Sekihara H. Lactoferrin reduces colitis in rats via modulation of the immune system and correction of cytokine imbalance. Am J Physiol Gastrointest Liver Physiol 2002;283:G187-G195.

57. Griffiths EA, Duffy LC, Schanbacher FL, Dryja D, Leavens A, Neiswander RL, Qiao H, DiRienzo D, Ogra P. In vitro growth responses of bifidobacteria and enteropathogens to bovine and human lactoferrin. Dig Dis Sci 2003;48:1324-1332.

\section{Author Affiliations}

Nidia León-Sicairos, DSc; Departamento de Biología Celular, Centro de Investigación y de Estudios, Avanzados del I.P.N. Apdo. 14-740, México, D. F. 07000, México; Hospital Pediátrico de Sinaloa, Depto. Investigación, Blvd. Constitución s/n, Col. Almada, Culiacán, Sinaloa 80200, México

Fernando López-Soto, MSc; Departamento de Biología Celular, Centro de Investigación y de Estudios, Avanzados del I.P.N. Apdo. 14-740, México, D. F. 07000, México

Magda Reyes-López, BSc; Departamento de Biología Celular, Centro de Investigación y de Estudios, Avanzados del I.P.N. Apdo. 14-740, México, D. F. 07000, México

Delfino Godinez-Vargas, MSc; Departamento de Biología Celular, Centro de Investigación y de Estudios, Avanzados del I.P.N. Apdo. 14-740,México, D. F. 07000, México

Cynthia Ordaz-Pichardo, DSc; Unidad Académica Multidisciplinaria Reynosa-Aztlán, Universidad Autónoma de Tamaulipas, Calle 16 y Lago de Chapala, Col. Aztlán, Reynosa, Tamps. 88710, México

Mireya de la Garza, DSc; Departamento de Biología Celular, Centro de Investigación y de Estudios, Avanzados del I.P.N. Apdo. 14-740, México, D. F. 07000, México 